\title{
DEVELOPING THE APPROACH OF E-SERVICES PROVIDING IN TERMS OF DECENTRALIZATION REFORM IN PUBLIC ADMINISTRATION SYSTEM OF UKRAINE
}

\author{
Anton Andriienko', Olga Matveieva²
}

\begin{abstract}
The purpose of the paper is to describe the approach of e-services providing in Ukraine in terms of decentralization reform. Methodology. We suggest describing the approach of e-services providing. According to the subject of description, methodology could be classified in groups presented below: description of the background (part 3), which reveals the need for digital education; analysis of digital transformation in public administration decentralization reform (part 4); strategic analysis of the vision for public e-services providing (part 5); generalization of the approaches (part 6). The development of the method of descriptive analyses has been based on several sources, namely: studies of the case of public e-services providing in Ukraine; analyses of extant literature on public e-services and their development. Results. Developing innovative and flexible public e-services in Ukraine, capable for adapting to the citizens' current needs, has become crucial for public administrations. Progress in e-Government tools implementation continues in Ukraine in terms of decentralization reform. The e-Government concept puts into practice as the ambition of Ukrainian decentralized government to use information and communication technology (ICT) to provide more efficient public e-services for citizens. The relationship between citizens and the local government is crucial and it is mediated through modeling the process of e-services developing and deeper understanding current citizens' needs by governmental officials. Practical implications. Our research aims at developing bases for strategic vision on public e-services in Ukraine as a framework that lays the foundations enabling a public administration to build flexible and innovative system of e-services, by relying on four bases (openness, participation, collaboration and integration). Value/originality. Revealing the current stage of decentralization reform of Ukraine enable to provide a case study of the organizational, institutional and social capacities for digitalization of e-services and form a strategic vision for their systemic development.
\end{abstract}

Key words: public administration, e-services, ICT, local government, strategic vision.

JEL Classification: H76, H83, L86

\section{Introduction}

E-services providing in public administration system of Ukraine have their peculiarities, which are grounded in terms of decentralization reform providing. Reconstruction of national economy, political crisis, exacerbation of armed conflict and other destructive factors affect balance in relationship between government and civic society. This situation requires the establishment of an effective system of e-services throughout Ukraine for restoration people's trust in the state.

Different aspects and the principles of e-services providing were analyzed in works by I. Bernhard
(2020), V. Boiko (2019), M. Chantillon (2019), J. Crompvoets (2019), M. Dolata (2020), S. Hunnius (2013), J. Kirchner (2017), R. Kruk (2019), V. Navumau (2014), A. Simonofski (2019), B. Schenk (2020), T. Schuppan (2013), T. Tombal (2019) and other scientists. Having analyzed the study of e-services providing, we can conclude that there is still the problem of significant digital gap which means a relatively low use of public e-services among most numerous group of Ukrainian population. This group is formed among older population and people who do not use Internet. As a result, statistics show a difference between the government's supply and people's use

\footnotetext{
Corresponding author:

${ }^{1}$ Dnipropetrovsk Regional Institute for Public Administration of the

National Academy for Public Administration of the President of Ukraine, Ukraine.

E-mail: a.andriienko@gmail.com

ORCID: https://orcid.org/0000-0001-7780-0557

${ }^{2}$ Dnipropetrovsk Regional Institute for Public Administration of the

National Academy for Public Administration of the President of Ukraine, Ukraine.

E-mail: olivebox30@gmail.com

ORCID: https://orcid.org/0000-0003-3344-1497
} 
of e-Government services, indicating problems with access to the Internet, usefulness of existing services and user satisfaction regarding public expectations. In fact, only $10.2 \mathrm{mln}$ Ukrainians constantly use most popular e-services from more than 50 available (E-services, 2020).

\section{Main results}

At the current stage of public administration and decentralization reform in Ukraine, that there is no high accessibility to Internet in Ukrainian rural communities. That is why they are not still as popular as non-electronic ones which are currently provided via 'open window' format by governmental institutions. Enhancing the use of e-services in such communities requires the creation of incentives for citizens while respecting spreading democratic principles such as territorial, gender and economic equity in access.

\section{Need for digital education}

Aspect of spreading democratic principles around e-services popularizing in Ukrainian communities requires focused knowledge providing. Focus should be put on collecting the information as well as about technology and services available.

The numerous citizen groups with low Internet use level or absence of Internet access are the elderly (over age 65), citizens with limited digital knowledge, and citizens with a low income. Internally displaced people also form a unique group of partially excluded persons due to disorientation and social exclusion. Many of the digitally excluded persons are those who need government services the most in Ukraine. The gap between those who regularly gets access and use e-services and those who do not use or have access at all is called a 'digital divide dilemma' (Bernhard, 2020). And this issue is not yet studied in Ukraine.

Today, Ukraine is a dynamically reformed state with numerous efforts of public services digitalizing and spreading best international practices in public administration in amalgamated territorial communities (Boiko, 2019; Navumau, 2014). The local democracy as a consequence of decentralization reform aims to relate people's choice and public administration for promoting constitutional freedoms on free services obtaining while considering interests and ideas of citizens by the government. This gives new opportunities for municipalities and rural communities to pay attention to and provide strategic plans in relation to local characteristics and meet the expanded needs of citizens.

Locality and subsidiarity are core values of new local management in the amalgamated territorial communities, as far as public revitalization of trust in local government, which strives to be open, inclusive and accessible for all social strata. Hence the implementation of e-services within decentralization reform seems to contribute to increased accessibility and openness of e-governance, even for those groups of citizens who have problems using Internet and access to local services. The results of reform could be also indicated by a development towards increasing equal treatment of citizens and a contribution to reducing problems related to the 'digital divide'. E-services should become more adapted to citizens' needs by using citizen-centric methods during the reformation and service contact-centers' tasks development. The development of territorial service contact-centers could be seen as indicators of local e-democracy building and e-governance, although there is still a need to go further in this direction (Bernhard, 2020).

In this aspect, digital education, as well as focusing knowledge on citizens' right for public services available, should be seen as an efficient tool of facilitating digital transformation of society. It could become an efficient way to enhance user engagement designed to fit the context of public administration. So, focused education might be the priority of government to tackle the slow digitalization processes in public administration (Schenk \& Dolata, 2020).

\section{Digital transformation in public administration during the decentralization reform}

Digital transformation is the modified use of digital technology to solve practical problems with e-services providing (World Economic Forum, 2017). It brings new types of innovative solutions, rather than simply supporting and extending traditional approaches. The essence of digital transformation in public services system is providing technology-based solutions to old (traditionally existing) and new social, economic and digital challenges.

There are numerous challenges in public administration, such as expanded demand and higher expectations from citizens and dependency on global and national political agendas. New challenges always require new solutions to which technologies should offer opportunities. But public sector often lacks scientific grounds, human and financial resources for exploration, choice, and implementation (Schenk \& Dolata, 2020). The stage of global digitalization results in developing websites of public institutes where the people could find and download all needed information and, hopefully, carry out basic transactions to get e-service on opened and transparent way. But digital transformation could be more than digitalizing basic services. To offer demanded high-quality public services, public administration should design and provide its e-services to an up-to-date level in technology and 
content, considering citizen's perspective. Their role facilitating digital transformation is also in guarantying social inclusion in public administration and local development. The public sector requires transparent and accessible mechanisms and simple management practices to regulate the transformation. This challenge provides an important managerial task - enhancing proactive and efficient public participation at the local level as a grass root of local democracy. It also objectivizes the task for government to provide well trained staff to drive the changes and to create problem-oriented interdisciplinary teams for meeting systemic modifications. The public sector in Ukraine lacks a consistent and citizen-friendly national strategy for digital transformation. It mostly relies on singular improvements of public services system as a part of national-wide public administration and decentralization reform. Implementing a proper digital-transformation strategy at the national and then at the local level requires the skilled professionals in e-service-oriented public administration.

Kirchner J. (2017) and Schenk B. \& Dolata M. (2020) identify 3 groups of competences expected to play a primary role in the upcoming digital transformation processes:

(a) Key non-digital competences: entrepreneurial thinking and self-initiatives, adaptability, creativity, problem-solving perseverance.

(b) Key digital skills \& competences: digital literacy, digital interaction, collaboration, data literacy, digital learning, digital ethics, agile working.

(c) Technological competences: technological skills, tech-translation (to moderate between non-technical experts and technical experts), user-centered design, web-design, complex data analysis, conception \& administration of networked IT systems, smart hardware/robotics design \& development, and blockchain technology.

The individual technological competences could be integrated into public administration via hiring private companies on the principles of state-privatepublic partnerships. In this format, the public sector could require key digital and non-digital competences for accommodation technological improvements at all organizational levels. However, Hunnius S. \& Schuppan T. (2013) suppose that these competences and skills are missing in the curricula of public administration schools and, hence, also in the public agencies and municipalities. It still remains the significant problem of Ukraine.

\section{Strategic vision for public e-services providing}

The objective of Ukrainian government's activity in this sphere is to develop a national Strategy for providing public e-services (Kruk, Chantillon,
Simonofski, Tombal \& Crompvoets, 2019). This objective encompasses the following sub-objectives: - to provide an overview of the current situation in the field of geographical public e-services in Ukrainian territorial communities;

- to identify current demand on e-services and local capacities for public services digitalization (Andriienko, 2019);

- to make a prognosis of future needs (Matveieva \& Shevchenko, 2019) of the users and to define the possible options which could be used to provide an answer to the changing public needs;

- to provide decisions on enhancing flexibility and innovativeness of local government as an e-services providers (Figure 1).

Conceptual base of strategy was built on Swedish experience of public services digitalization. Ukrainian case of this system reforming puts focus on 4 strategic principles of public e-services providing:

1. Openness.

2. Participation.

3. Collaboration.

4. Integration (Figure 2).

Openness includes guaranteeing personal data protection and security, sharing information and services as broadly as possible, when possible for free. It also means increasing the level of transparency and foster national growth through collaboration and data sharing while generation value-added services. It implies fundamental data governance reflections, rethinking the information management system is a pre-requisite for achieve safe and efficient openness.

Participation means involving all stakeholders impacted by the digitalisation, through considering their needs, ideas, requirements and opportunities for participation. This could enable local governance to meet expectations of the stakeholders. Two main stakeholder groups include the external users (1) - citizens or public sector organisations and internal public servants as users (2), whose jobs will evolve due to the digitalisation. First group (1) could have to participate in the development of e-services directly. Due to public participation, e-services could be better aligned with stakeholder's requirements and, therefore, more widely used. Second group (2) interacts with the e-services via back-office, which is essential to accompany changes with appropriate management actions (Andriienko, 2019).

Collaboration foresees the administration's embracing a globalizing society, in which they act as co-working actors with wide perspective towards cooperation, data sharing and capacity building to fulfill the work tasks towards a variety of stakeholders. Organizations-providers restructure their cooperation via interrelated partnerships within common strategic vision (Kruk, Chantillon, Simonofski, Tombal \& Crompvoets, 2019). 


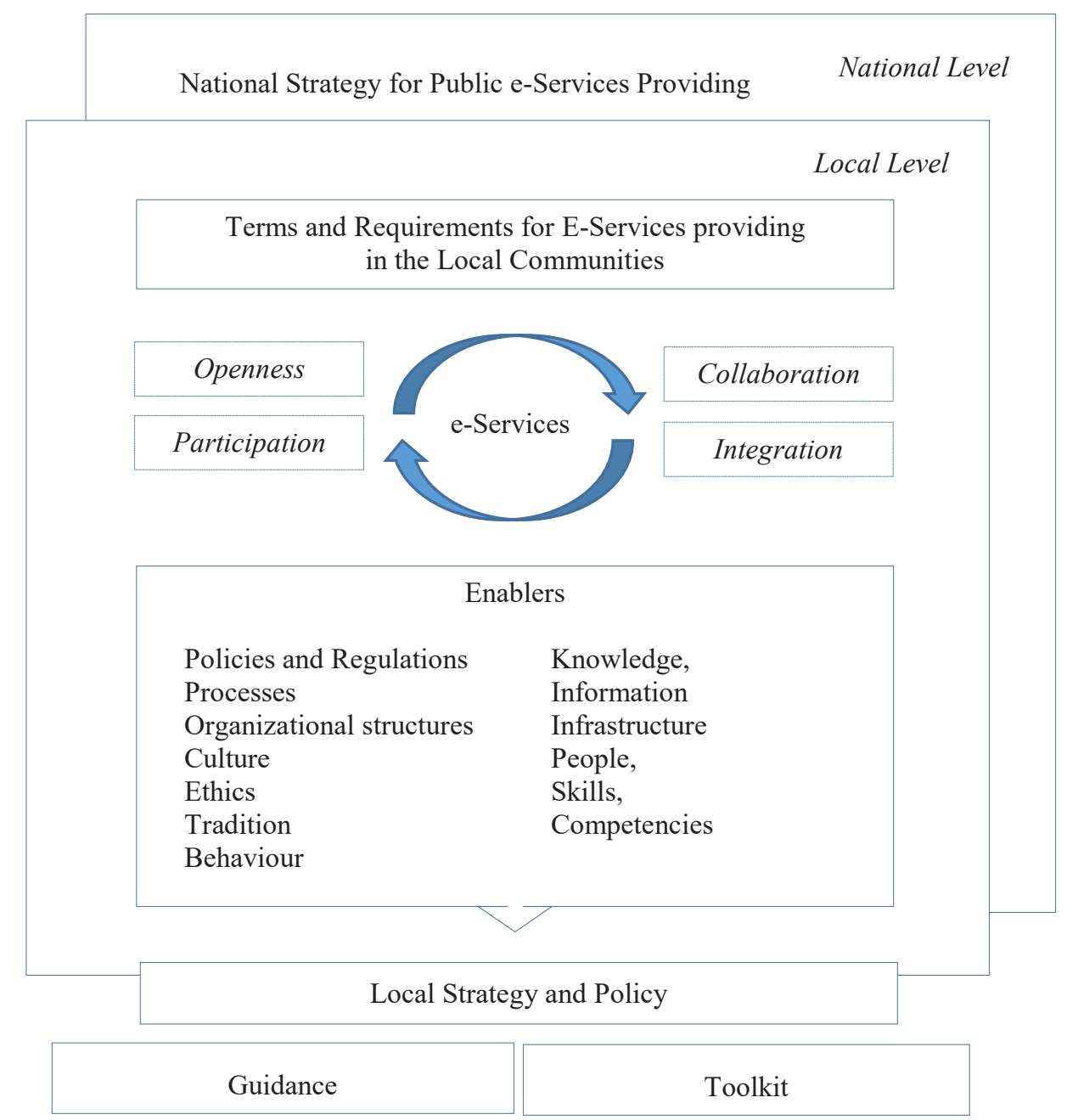

Figure 1. Framing the Role of Strategy for Public e-Services Providing

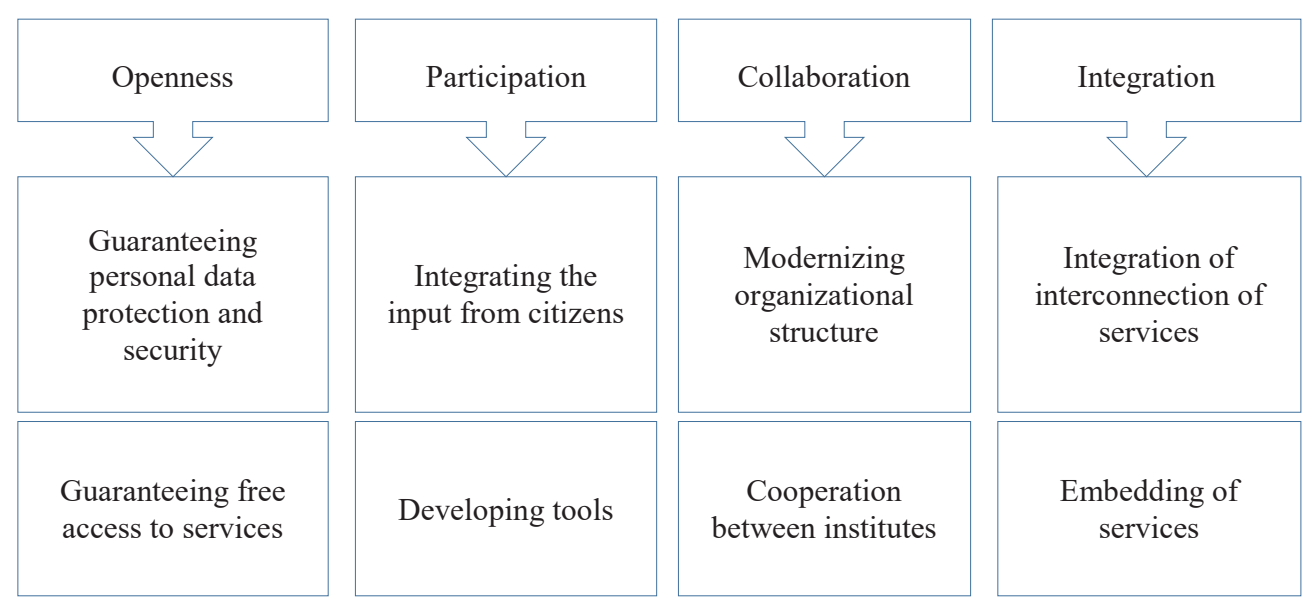

Figure 2. Basic Conceptual Principles of Public e-Services Providing

Integrated information and communication systems in public administration can enable better decisionmaking and improve the added value of services that the administration pursues. It also implies finding the balance between budgetary autonomy and user orientation.

\section{Conclusion}

Developing public e-services in Ukraine on the way of enhanced innovativeness, accessibility and flexibility foresees from public administrators meeting of numerous challenges, such as expanded demand and higher expectations from citizens, as far as deepening 
dependency on global and national political agendas. On the one hand, this task implies updating knowledge and skills of e-services users to increase public participation in e-policy framing. On the other hand, it requires clear strategic vision for all stakeholders (citizens, public administrators, organizations) put in the national strategy. Developing the basics for framing strategic vision on public e-services in Ukraine lays in the sphere on enabling public administration to build flexible, integrative and innovative system of e-services through the strategic principles of openness, participation, collaboration and integration. Following these principles during development of the strategic vision and documenting the strategy of public e-services providing could allow to make public administration more user-centric and demand-oriented.

\section{References:}

Andriienko, A. (2019). Prospects of globalized smart approaches implementation in the development of large cities in Ukraine in the context of Ukrainian experience. Theoretical and methodological approaches to the formation of a modern system of enterprises, organizations and institutions' development. Available at: https://ojs.ukrlogos.in.ua/index.php/monographs/article/view/431 Ukrlogos

Bernhard, I. (2020). Incentives for Inclusive E-Government: The Implementation of Contact Centers in Swedish Municipalities: Open Government: Concepts, Methodologies, Tools, and Applications. Available at: https://www.igi-global.com/chapter/incentives-for-inclusive-e-government/235174

Boiko, V. (2019). EU Cyber Public-Private Partnerships (cPPP): Approaches to Formation and Legal Framework. Strategic Panorama. Available at: https://www.academia.edu/35221560/EU Cyber Public-Private Partnerships_cPPP_Approaches_to_Formation_and_Legal_Framework?source $=$ swp_share

E-services (2020). Cabinet of Ministers of Ukraine. Available at: https://www.kmu.gov.ua/en

Hunnius, S. \& Schuppan, T. (2013). Competency Requirements for Transformational E-Government. Proc. HICSS.

Kirchner, J. et al. (2017). Future Skills: Which skills are lacking in Germany. Stifterverband für die Dt. Wissenschaft.

Kruk, R., Chantillon, M., Simonofski, A., Tombal, T., \& Crompvoets, J. (2019). FLEXPUB: Developing a Strategy for Flexible and Innovative e-Services. Data for Policy. Digital Trust and Personal data. London: University College. Available at: https://www.researchgate.net/publication/333732108_FLEXPUB Developing_a_Strategy_for_Flexible_and_Innovative_e-Services

Matveieva, O., \& Shevchenko, L. (2019). Analysis of the situation and trends in foreign trade of Dnipropetrovsk region: challenges and opportunities for the sustainable regional growth. Public Administration Aspects, vol. 9-10, pp. 79-87. Available at: https://aspects.org.ua/index.php/journal/article/view/684

Navumau, V. (2014). Electronic experience of Georgis for Belarus. E-gov.by. Available at: http://e-gov.by/bestpractices/elektronnyj-opyt-gruzii-dlya-belarusi

Schenk, B., \& Dolata, M. (2020). Facilitating digital transformation through education: A case study in the public administration, 53rd Hawaii International Conference on System Sciences, 2134-2144. Available at: https://scholarspace.manoa.hawaii.edu/bitstream/10125/64003/0212.pdf

World Economic Forum (2017): The Digital Transformation Initiative. Geneva: WEF. 